\title{
Seismic response of SSSI system: surface structures and subway
}

Yu Miao

Professor, School of Civil Engineering and Mechanics, Huazhong University of Science and Technology, Wuhan, China

\section{Yi Zhong}

Master's student, School of Civil Engineering and Mechanics, Huazhong University of Science and Technology, Wuhan, China

\section{Xixi Chen}

Associate Professor, School of Mechanical Science and Engineering,

Huazhong University of Science and Technology, Wuhan, China

(corresponding author: junoskinner@163.com)

\section{Bin Ruan}

Postdoctoral Researcher, School of Civil Engineering and Mechanics,

Huazhong University of Science and Technology, Wuhan, China

The seismic response of an underground structure is analysed in the time domain by considering the non-linearity of soil and the structure-soil-underground structure interaction. A three-dimensional model that comprises a subway station and adjacent surface frame structure with a pile foundation and soft clay is established. The modified Davidenkov model is used to simulate the non-linearity of soft clay, which is then further developed using the commercial software Abaqus. This study focuses on the influence of adjacent surface frame structures on the seismic response of a subway station in the time domain. The interstorey drift ratio of the subway station is selected to evaluate the correlation effect in this complicated system. The influence factors, including the horizontal distance between the frame structures and subway station, length of the pile foundation, orientation of the frame structure and burial depth of the subway station, are discussed in the paper. Numerical results indicate that horizontal distance and burial depth are two of the key factors that may evidently amplify or attenuate the seismic response of an underground structure.

\section{Notation}

$d \quad$ horizontal distance between the frame structure and subway station: $m$

$H \quad$ height of a storey: $\mathrm{m}$

$H_{\mathrm{s}} \quad$ thickness of the soil

$h$ buried depth of the subway station: $m$

$l \quad$ length of the pile foundation: $m$

$\Delta U$ peak displacement difference at the side-plate of the subway station

$\Delta u \quad$ maximum displacement difference between two adjacent floors across the floor plane: $m$

$\theta \quad$ interstorey drift ratio

$\phi \quad$ angle between the longitudinal axis of the frame structure and subway station: ${ }^{\circ}$

\section{Introduction}

Subway stations were once believed to be insusceptible to earthquakes. Nevertheless, due to several severe seismic events (e.g. the 1995 Kobe earthquake, the 1999 Kocaeli earthquake, the 1999 Chi-Chi earthquake and the 2008 Wenchuan earthquake), the necessity of a seismic design for subway stations has been recognised (Bobet et al., 2008; Hashash et al., 2001) in seismic areas. The seismic behaviour of subway stations has been analysed for a long time. A system with a single underground structure embedded into soil is the typical simplified model used by numerous researchers, including Chen et al. (2013, 2015), to represent the seismic problem of subway stations. However, this model considers only the correlation effect between the soil and the subway station. In such a coupled system, this effect is called soil-structure interaction (SSI). Many scholars have made remarkable contributions (Luco and Westmann, 1971, 1972; Reissner, 1936) to this issue, particularly to its inchoate development process. The practical application of various methods, such as the finite-element method (FEM) and boundaryelement method, and the rapid development of computer technology have accelerated the development of SSI analysis. Further studies on SSI (Azadi and Hosseini, 2010; Hatzigeourgiou and Beskos, 2010; Miao et al., 2016; Romanel and Kundu, 1993) have been conducted in recent decades. The history and current status of SSI were elucidated by Kausel (2010).

Apart from soil, however, a subway station is dependent on other elements in its surroundings. Adjacent surface buildings and roads also impact on the seismic behaviour of a subway station. The impact on the elements of a multistructure system through soil is called structure-soil-structure interaction (SSSI). The analysis of the dynamic response of a subway station during an earthquake has become increasingly difficult due to the existence of adjacent surface structures.

Previous studies on SSSI (Aldaikh et al., 2015, 2016; Behnamfar and Sugimura, 1999; Kobori and Kusakabe, 1978, 1980; Warburton et al., 1971, 1972) have mostly focused on either superstructures or underground structures. Only a few studies have simultaneously considered underground and adjacent surface structures. Yang et al. (2007) conducted an analysis on the seismic response effect of a tunnel to nearby structures. Guo et al. (2013) investigated the interstorey drift ratio of adjacent surface structures by considering the existence of a subway station with a two-dimensional (2D) model. Recently, the correlation effect law between adjacent surface and underground structures was investigated in the frequency domain by Wang et al. $(2013,2017)$.

The seismic behaviour of a subway station can be seriously affected by soil properties. Most of the previous analyses on SSSI 
are limited to frequency-domain analyses, which are less time consuming but can be conducted only under linear conditions. However, the non-linear behaviour and other properties of the soil cannot be disregarded on various occasions. Time-domain analysis, which can use time as a coordinate to express the relationship among parameters, can consider the non-linearity and other properties of soil. Time-domain analysis is an important supplement to frequency-domain analysis. Previous studies in the time domain, such as those of Hatzigeorgiou and Beskos (2010), Abate and Massimino (2017a, 2017b) and Abate et al. (2016), were nearly always conducted on a single structure or with a $2 \mathrm{D}$ model. Hence, an analysis of the seismic response of a subway station in the time domain that considers the non-linearity of soil and SSSI with a three-dimensional (3D) model is necessary.

The problem is stated and the basic parameters of the 3D numerical model of SSSI are described in the next section. Subsequently, the 3D model of a surface structure-soil-underground structure system that considers the non-linearity of soil is established by way of FEM. Ground motion is inputted to analyse the seismic response of a subway station. The influence of factors, including the horizontal distance between the frame structures and subway station, length of the pile foundation, orientation of the frame structure and burial depth of the subway station, on the interstorey drift ratio of a subway station is presented in the form of time-domain curves and formulas.

\section{Problem definition}

Here, the system under study comprises a subway station and an adjacent surface frame structure with a pile foundation and soft clay that exhibits a non-linear behaviour. This investigation is focused on the seismic response of the subway station under different arrangement and size parameters.

The parameters of each component of the surface frame structure are as follows: the number of storeys is ten; the height of each storey is $3.6 \mathrm{~m}$; the cross-sections of the frame column and frame beam are $600 \mathrm{~mm} \times 600 \mathrm{~mm}$ and $250 \mathrm{~mm} \times 600 \mathrm{~mm}$, respectively; the diameter of the pile is $600 \mathrm{~mm}$; the length of the pile is $18 \mathrm{~m}$; and the thickness values of the floor slab and base

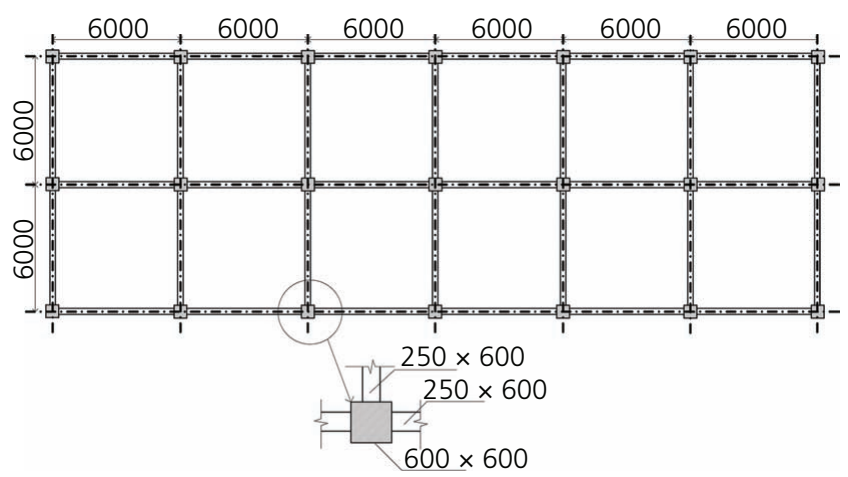

Figure 1. Typical cross-section of adjacent surface structure (dimensions: $\mathrm{mm}$ ) plate are 150 and $500 \mathrm{~mm}$, respectively. A typical cross-section of the surface structure is shown in Figure 1. A subway station in Shanghai is selected to establish the subway station model. The length of the station is $72 \mathrm{~m}$, and its cross-section and profile are shown in Figures 2 and 3, respectively. The Poisson's ratio of concrete is $0 \cdot 2$. Its modulus is $3.45 \times 10^{4} \mathrm{MPa}$, except for the pile

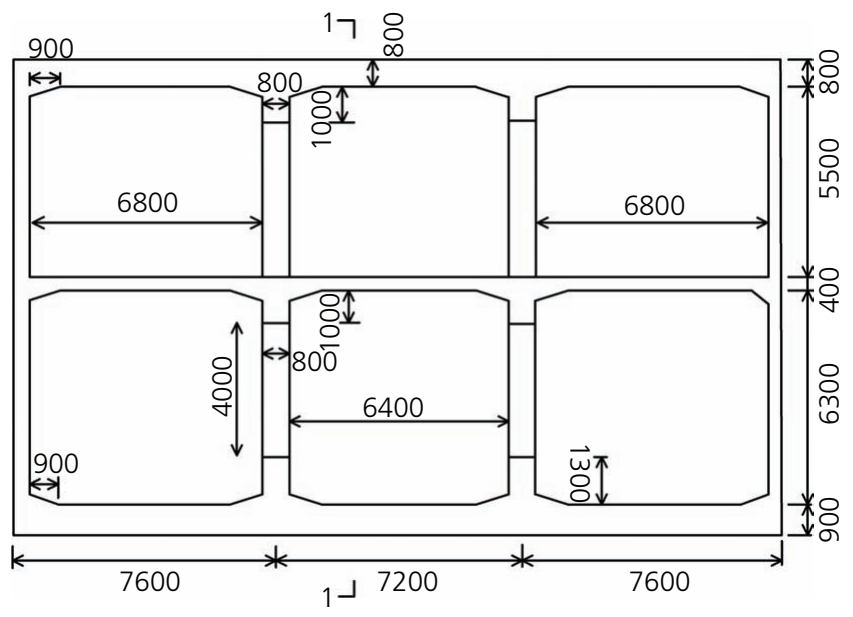

Figure 2. Cross-section of subway station (dimensions: $\mathrm{mm}$ )

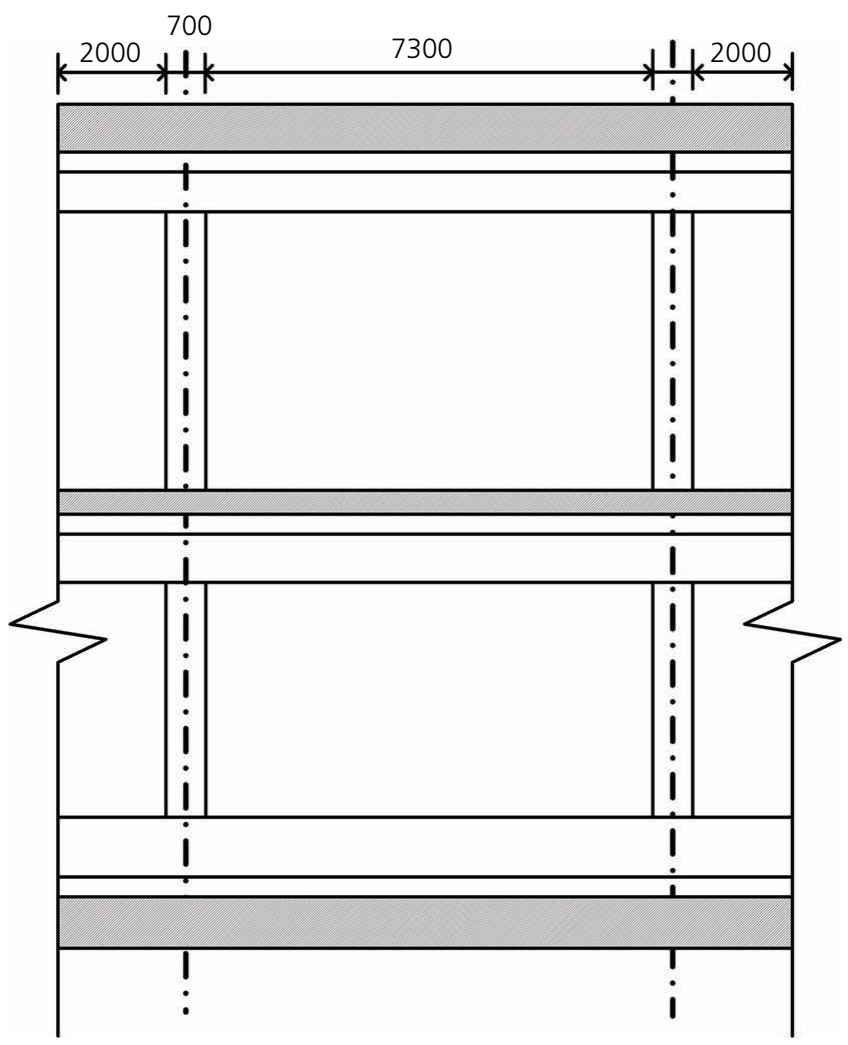

Figure 3. Profile of cross-section 1-1 of the subway station (dimensions: $\mathrm{mm}$ ) 
foundation, which has a modulus of $3.0 \times 10^{4} \mathrm{MPa}$. Moreover, the elastic parameters of soil are as follows: mass density is $1980 \mathrm{~kg} / \mathrm{m}^{3}$ and Poisson's ratio is $0 \cdot 485$.

The seismic behaviour of the subway station with different arrangement and size parameters is discussed in this section. A different arrangement is realised by changing the horizontal distance $(d)$ between the frame structure and subway station, orientation of the frame structure (represented by the angle $(\phi)$ between the longitudinal axis of the frame structure and subway station) and buried depth $(h)$ of the subway station. Meanwhile, a different size is obtained by changing the length $(l)$ of the pile, as shown in Figure 4. To explore the extent of the impact of these factors on the seismic response of the subway station that considers SSSI, the seismic responses of the subway station are compared under different parameter conditions.

\section{Finite-element model}

The finite-element model of the surface structure-soil-underground structure system is established and analysed in the time domain using general finite-element software, namely, Abaqus, as shown in Figure 5.
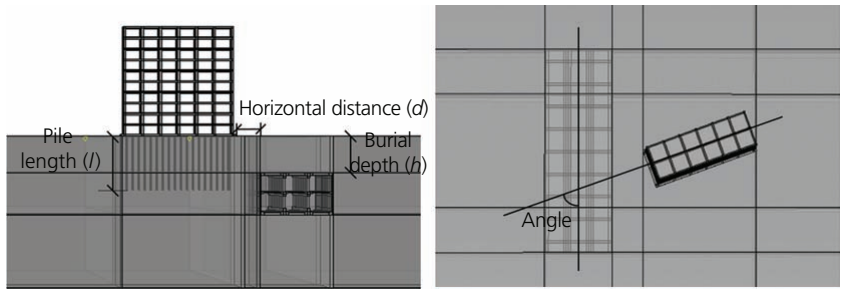

Figure 5. Influence factors in the finite-element model

The surface frame structure and subway station are modelled by solid elements, except for the pile foundation, which is modelled by beam elements. Several dynamic constitutive models of soil (Liu and Ling, 2008; Liu et al., 2006, 2014; Macari et al., 2003; Martin and Seed, 1982) have been proposed in the past decades. These models can simulate the dynamic behaviour of various types of soil. Here, the three-parameter modified Davidenkov model (Zhao et al., 2017) is used as the constitutive model of soft clay. This modified model can efficiently describe the non-linear dynamic characteristics of all types of soil, and the accumulated test data are abundant. This model follows the rule of the "upper
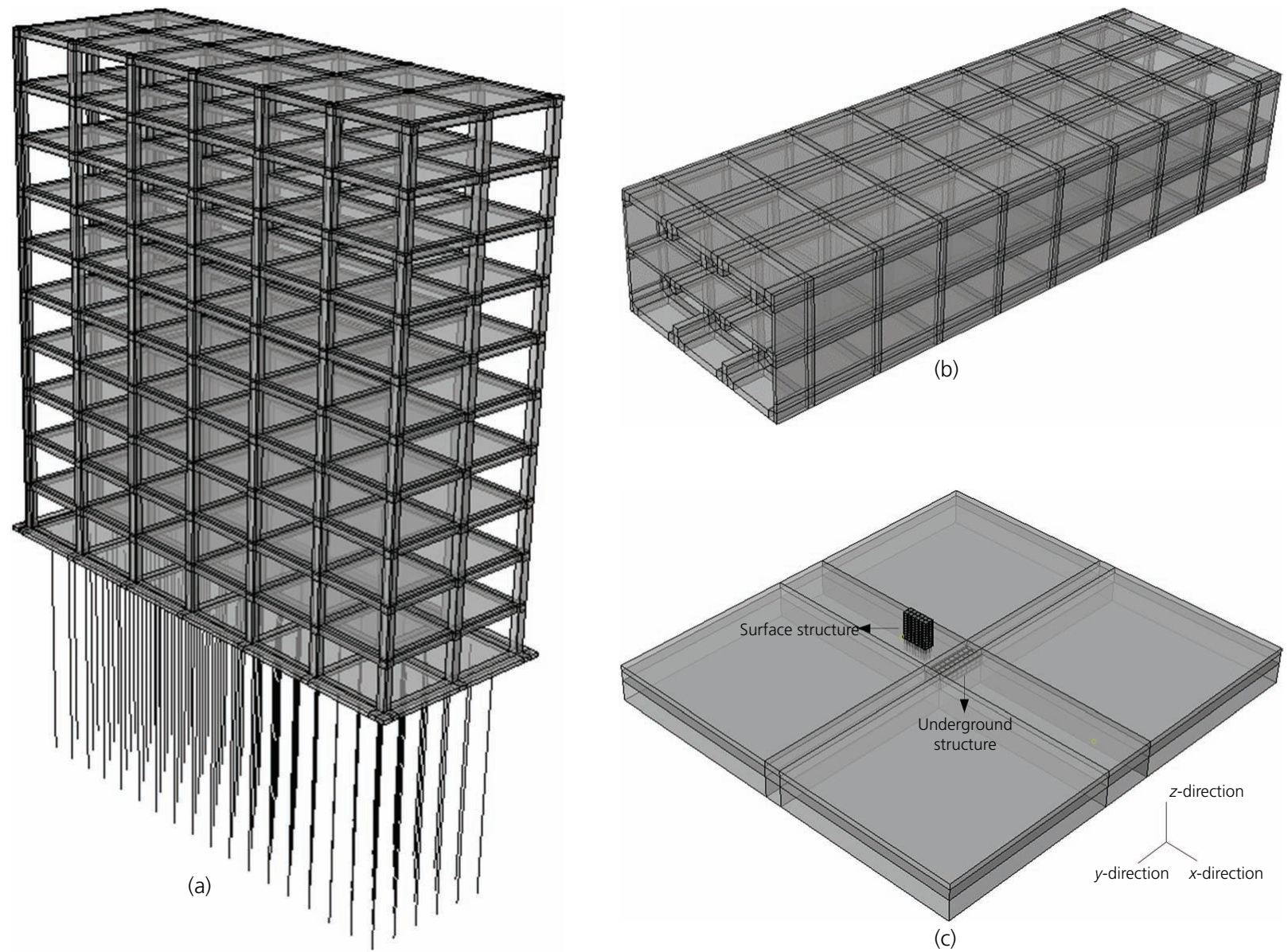

Figure 4. Finite-element model: (a) surface structure; (b) underground structure; (c) surface structure-soil-underground structure system 
skeleton curve' in the 'extended Masing' rule and modifies the loading and unloading criteria of the hysteresis curve based on the ' $n$ times method' proposed by Pyke et al. (1979), thereby solving the problem of the extended Masing rule requiring a large storage space. Furthermore, the modified model improves the equivalent strain algorithm, which enhances computational efficiency without losing computational accuracy. The stress-strain curve of the modified Davidenkov soil model is shown in Figure 6. Three parameters are required to define a kind of soil using this soil model: $A, B$ and $\gamma$, whose meaning can be referred to in the paper by Zhao et al. (2017). Here, the values of those parameters are 1, 0.35 and 0.000967631 , respectively. A tie contact condition, which is used to connect two faces so that the nodes of the slave face have the same physical quantity as those of the master face, is assumed between the subway station and the surrounding soil given that the subway station moves along with the soil around it under ground motion. The surface frame structure and pile foundation also exhibit the same phenomenon. The piles are embedded into the soil.

The scope of the soil is set to be sufficiently large to avoid using artificial boundaries, increase computational efficiency and meet the conditions of semi-infinite space (Wang et al., 2017). The boundary of the surface frame structure and subway station is over $5 H_{\mathrm{s}}$ long of that of the soil, where $H_{\mathrm{s}}$ is the thickness of the soil, set at $50 \mathrm{~m}$. An El Centro wave with an acceleration peak of $0 \cdot 1 \mathrm{~g}$ is selected as the seismic input, applied in the $x$-direction as shown in Figure 4(c), and its time history of acceleration is shown in Figure 7.

\section{Numerical results}

The 3D model of the surface structure-soil-underground structure system is described in the previous section. Subsequently, the influences of four parameters - namely, horizontal distance between the frame structures and subway station, length of the

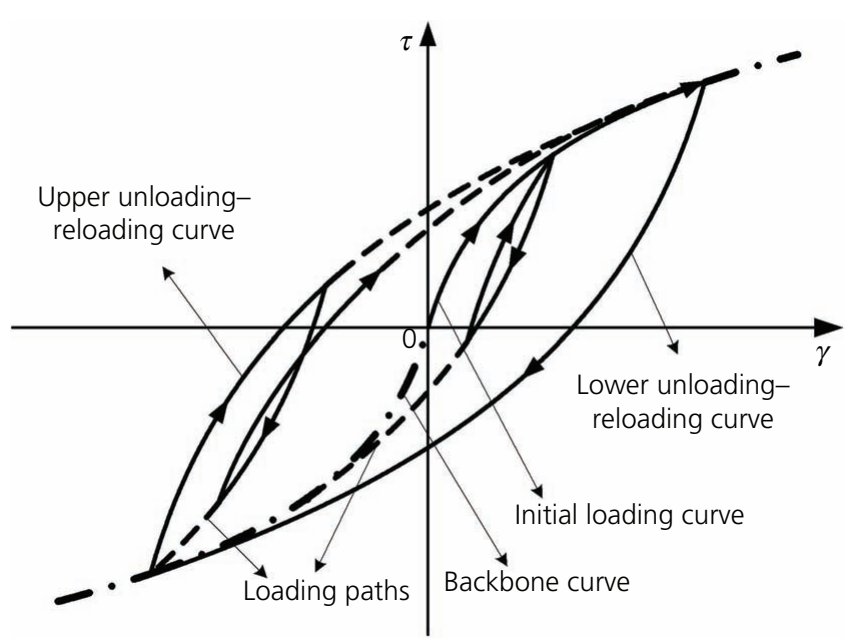

Figure 6. Stress-strain curve of the modified Davidenkov soil model (Zhao et al., 2017)

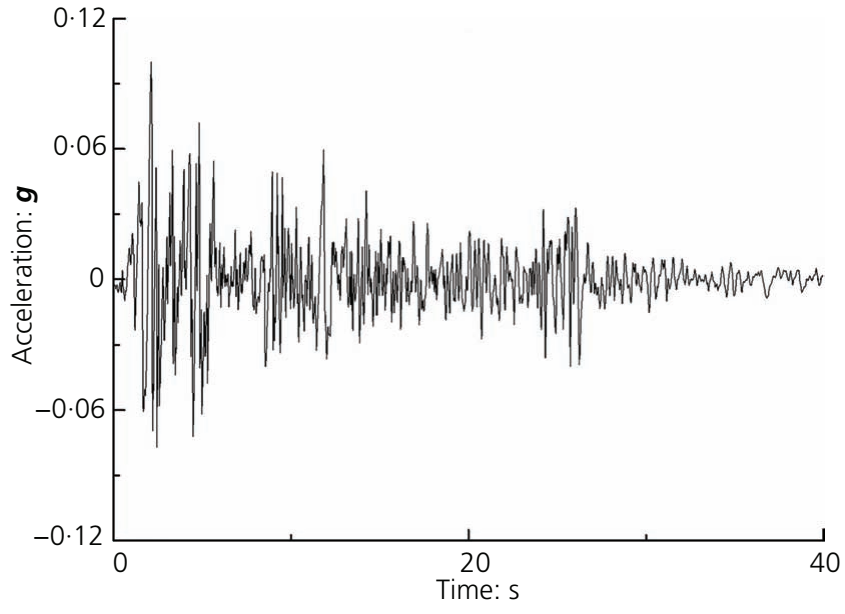

Figure 7. Acceleration time history of El Centro wave

pile foundation, orientation of the frame structure and burial depth of the subway station - on the response of the underground structure are discussed in this section. Here, the interstorey drift ratio $\theta$ is selected as the index to evaluate the correlation effect in such a complicated system, which is defined as $\Delta u / H$, where $\Delta u$ is the maximum of the displacement difference between two adjacent floors across the floor plane and $H$ is the height of a storey. To determine the law of the correlation effect, various seismic responses of the subway station are analysed and contrasted under different parameter conditions. The controlling variable method, in which only one of the factors is changed while the other variables are controlled to remain constant, is used in the next four sections to investigate the impact of the selected factors for multifactorial (multivariable) questions. Several figures are provided in the following sections to show the influences of the four parameters. The length of the pile foundation is $18 \mathrm{~m}$, the frame structure is perpendicular to the subway station, the thickness of the soil coverage is $8 \mathrm{~m}$ and the horizontal distance is $12 \mathrm{~m}$, when those parameters are controlled to remain constant.

\section{Effect of horizontal distance}

Here, the horizontal distance $(d)$ between the adjacent frame structure and subway station is changed while the other three variables are controlled to remain constant. The horizontal distance varies from 5 to $40 \mathrm{~m}$. The calculation results of the model are extracted to draw curves. The time history curves (Figures 8 and 9) show that the responses of the interstorey drift ratio at different horizontal distances are similar in shape. To reflect clearly the distinction of the interstorey drift ratio, the details of the interstorey drift ratio responses of the station are presented on an enlarged scale in Figures 10 and 11. These responses are selected during the pre- and post-peaking phases, thereby showing difference in amplitude. Peak points, including the positive maximum and negative maximum, are connected by lines in Figures 12 and 13 to investigate the impact of the interstorey drift ratio on the peak value. The interstorey drift ratio 


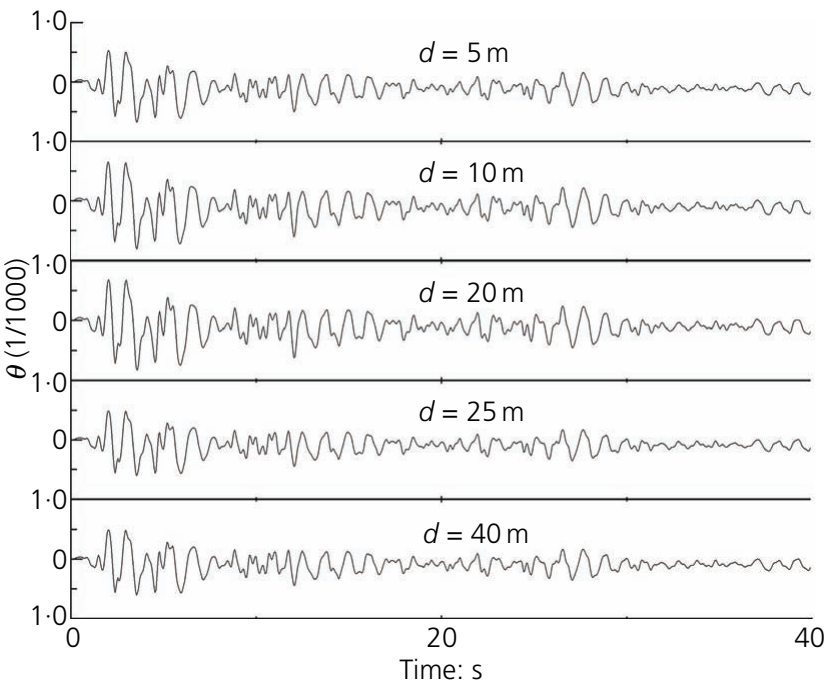

Figure 8. Interstorey drift ratio responses of the first floor of the station (horizontal distance changed)

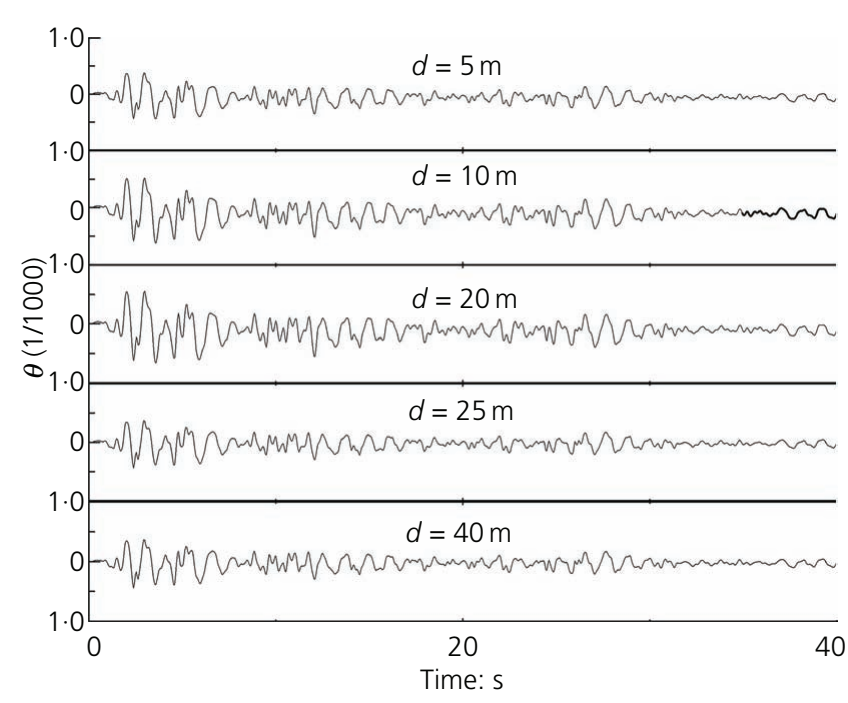

Figure 9. Interstorey drift ratio responses of the second floor of the station (horizontal distance changed)

response of the subway station is fluctuating, but not monotonous, under different conditions of horizontal distance between the two structures. In addition, when the distance is sufficiently far, the influence of adjacent surface structures on the response of the subway station is minimal and the maximum interstorey drift ratio is a constant.

\section{Effect of pile length}

The pile foundation is also likely to affect the seismic response of the subway station. The controlling variable method is used as described earlier to study the effect of pile length $(l)$ on the seismic response of the subway station. Here, the length of the

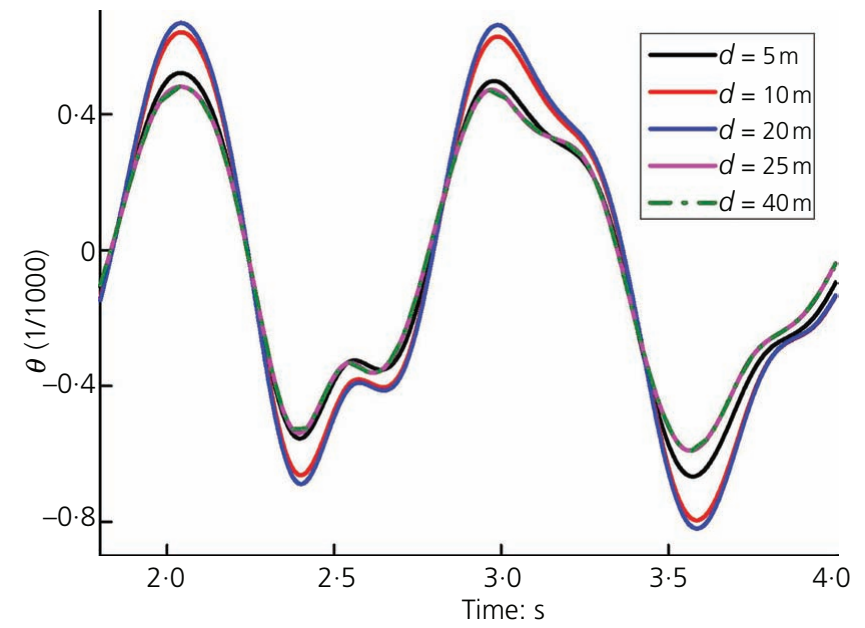

Figure 10. Detail with an enlarged scale of the peak interstorey drift ratio response of the first floor of the station (horizontal distance changed, 1.8-4s)

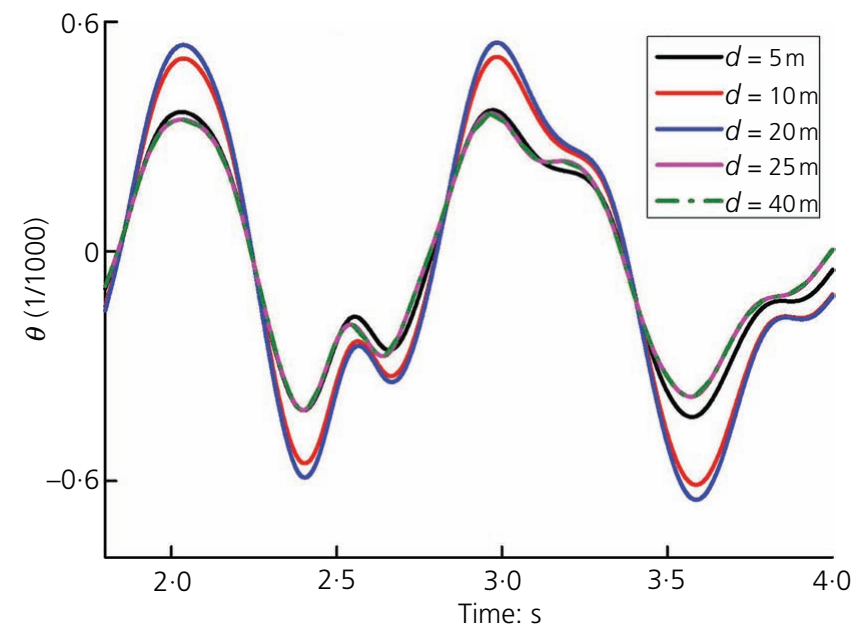

Figure 11. Detail with an enlarged scale of the peak interstorey drift ratio response of the second floor of the station (horizontal distance changed, 1.8-4 s)

pile foundation is changed from 0 to $24 \mathrm{~m}$ by $6 \mathrm{~m}$ intervals. The time history curves of the interstorey drift ratio nearly overlap although the length of the pile changes, which differs only slightly when the length of the pile is $24 \mathrm{~m}$. The line of the maximum interstorey drift ratio of the first floor rises slightly at the end, as shown in Figure 14, and the line that connects the maximum interstorey drift ratio of the second floor is nearly horizontal, as shown in Figure 15. When the time history curves are the same in terms of shape and amplitude, the influence of pile length on the interstorey drift ratio of the station can be disregarded. The comparison of the results presented in Figure 8 and those of Wang et al. (2017) shows that the influence of pile length on the seismic response of underground structures in the 


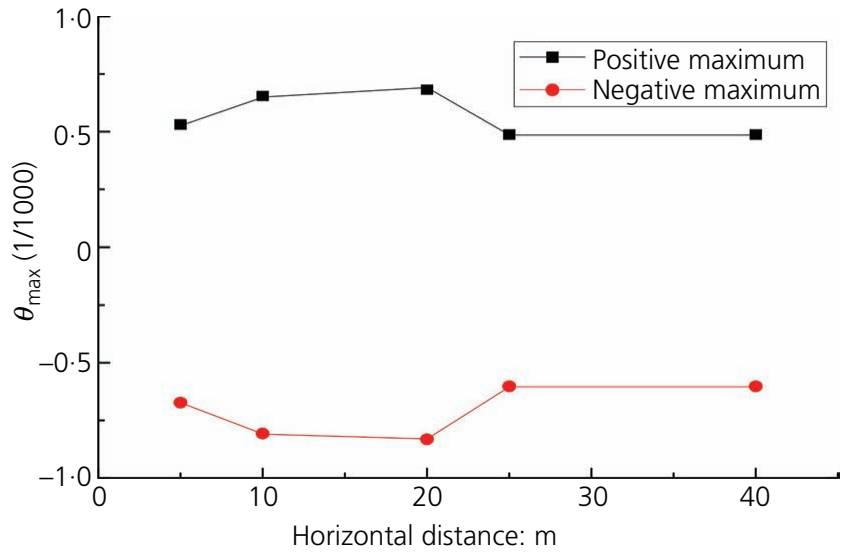

Figure 12. Variation in the maximum interstorey drift ratio of the first floor of the station with horizontal distance to the structure

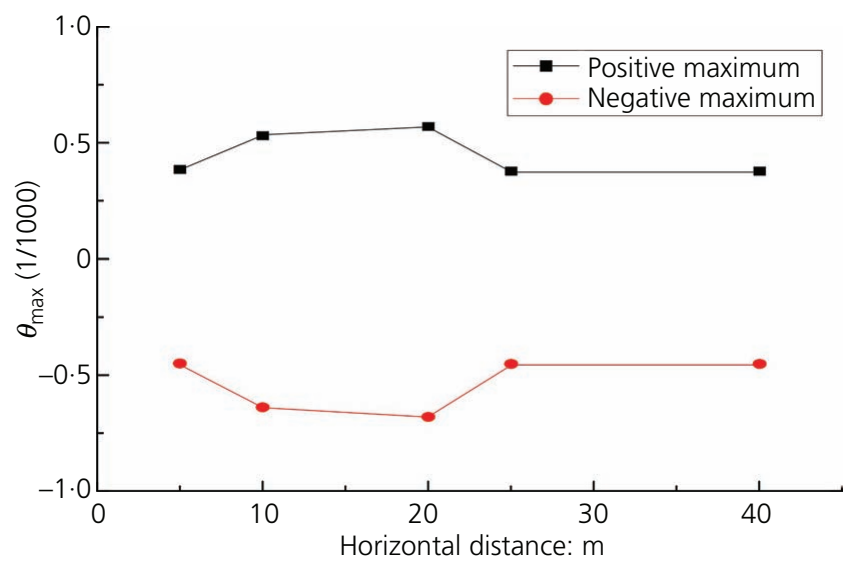

Figure 13. Variation in the maximum interstorey drift ratio of the second floor of the station with horizontal distance to the structure

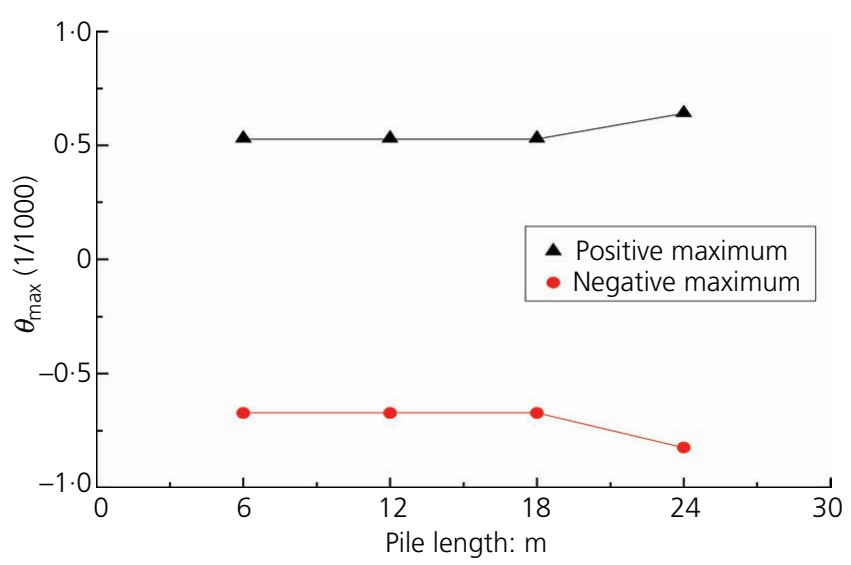

Figure 14. Variation in the maximum interstorey drift ratio of the first floor of the station with the pile length of the structure

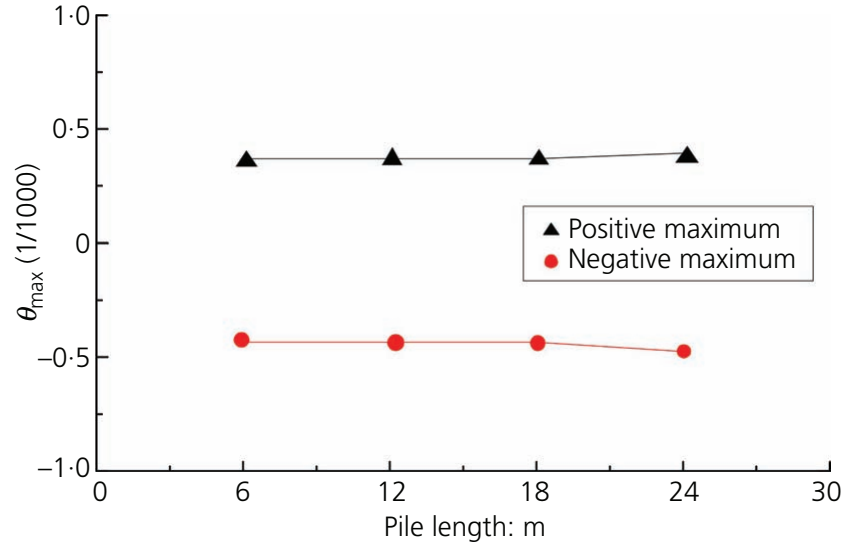

Figure 15. Variation in the maximum interstorey drift ratio of the second floor of the station with the pile length of the structure

frequency and time domains is relatively limited and nearly negligible.

\section{Effect of orientation}

Another important parameter that may have an impact on seismic response is the orientation of the frame structure, which is represented by the angle $(\phi)$ between the longitudinal axis of the subway station and frame structure. Here, $\phi$ is changed for modelling and calculation, whereas the other three factors remain unchanged. The responses of the interstorey drift ratio at different orientations of the frame structure in the time domain show a similarity in shape and a difference in amplitude. In Figures 16 and 17 , the curve of the interstorey drift ratio is nearly coincident when the angle is $0-60^{\circ}$, whereas the value of the interstorey drift ratio decreases when the angle increases to 70 and $80^{\circ}$. The response rises and reaches the maximum value when the frame structure is perpendicular to the subway station $\left(\phi=90^{\circ}\right)$. That is, the response remains constant in the beginning, then decreases and finally increases to the maximum value with an increasing

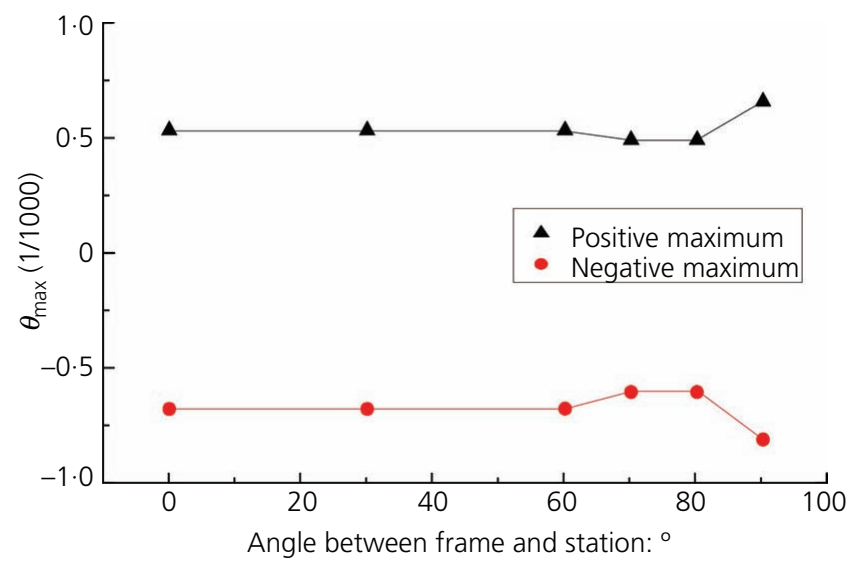

Figure 16. Variation in the maximum interstorey drift ratio of the first floor of the station with orientation to the structure 


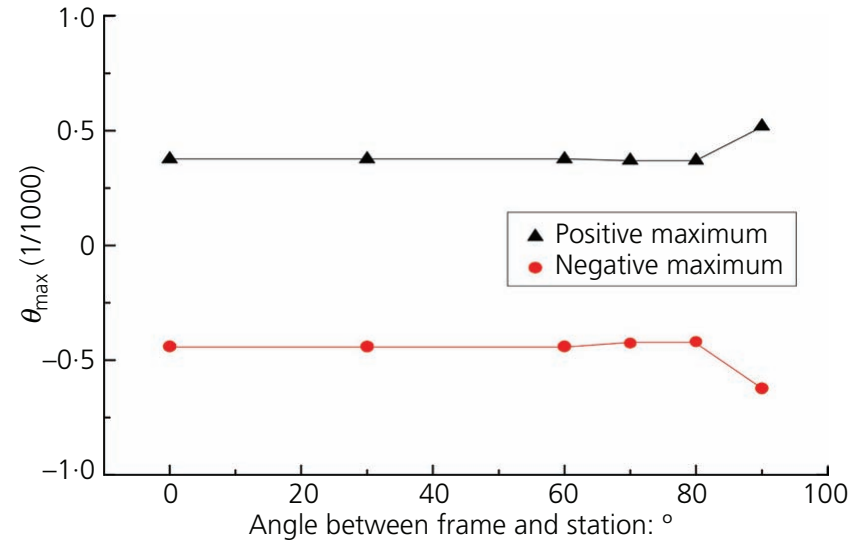

Figure 17. Variation in the maximum interstorey drift ratio of the second floor of the station with orientation to the structure

angle. Moreover, the minimum value appears between 70 and $80^{\circ}$, which is consistent with the case in which the diagonal of the frame horizontal plane is perpendicular to the longitudinal axis of the subway station - that is, approximately $72^{\circ}$. The reason for the appearance of a minimum may be that in this case, the stiffness of the surface structure in the $x$-direction is the greatest and the strengthening effect of the pile on the soil is the most significant, which limits the movement of the underground structure in the $x$-direction.

\section{Effect of burial depth}

Subway stations may be constructed at different depths to meet requirements in topography, transportation and urban spatial arrangement, among others. The seismic responses of the subway station may also vary under different depth conditions. In this section, the subway station's burial depth $(h)$ ranges from 4 to $25 \mathrm{~m}$, while the other parameters remain constant. Three seismic waves with different peak accelerations, $0 \cdot 1 \boldsymbol{g}, 0 \cdot 2 \boldsymbol{g}$ and $0 \cdot 3 \boldsymbol{g}$, are chosen as the input earthquake motions, to simulate earthquakes with different intensities. To investigate the relationship between the seismic response of the subway station and the burial depth, the displacement difference at the side-plate was chosen as the indicator, which represents a meaning similar to the interstorey drift ratio. The responses in either the time history curve or the partial enlargement differ considerably from each other in terms of amplitude, thereby indicating that this parameter has a major impact on the seismic response of the subway station. The peak displacement differences at the side-plate of the subway station, defined as $\Delta U$, with different burial depths are shown in Figures 18 and 19. Obviously, the relationship between the peak displacement difference of the station and burial depth can be described effectively by linear equations when the acceleration peak is $0 \cdot 1 \boldsymbol{g}$. While when the peak acceleration is $0 \cdot 2 \boldsymbol{g}$ or $0 \cdot 3 \mathrm{~g}$, the peak displacement difference increases with the increase in burial depth overall and declines when the burial depth is $12 \mathrm{~m}$. There are two factors affecting the displacement response of the subway station: one is the constraint of the surrounding soil and

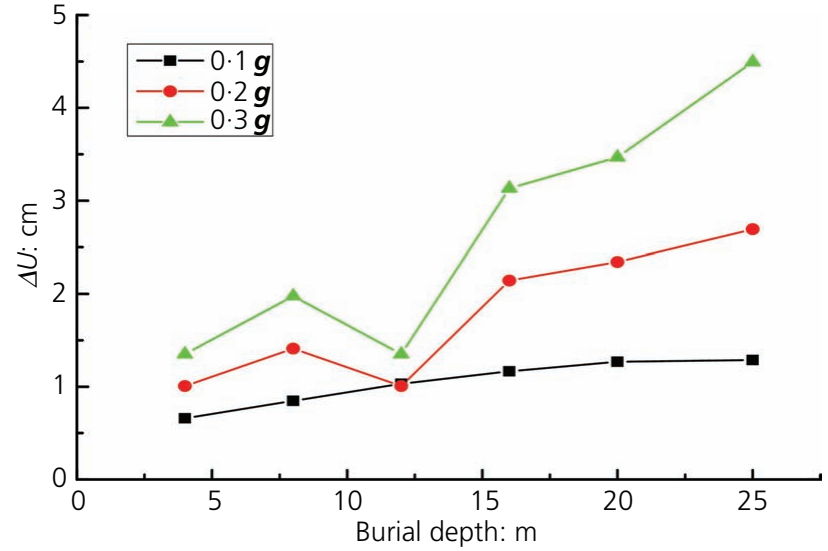

Figure 18. Variation in positive peak displacement difference at the side-plate of the subway station with burial depth

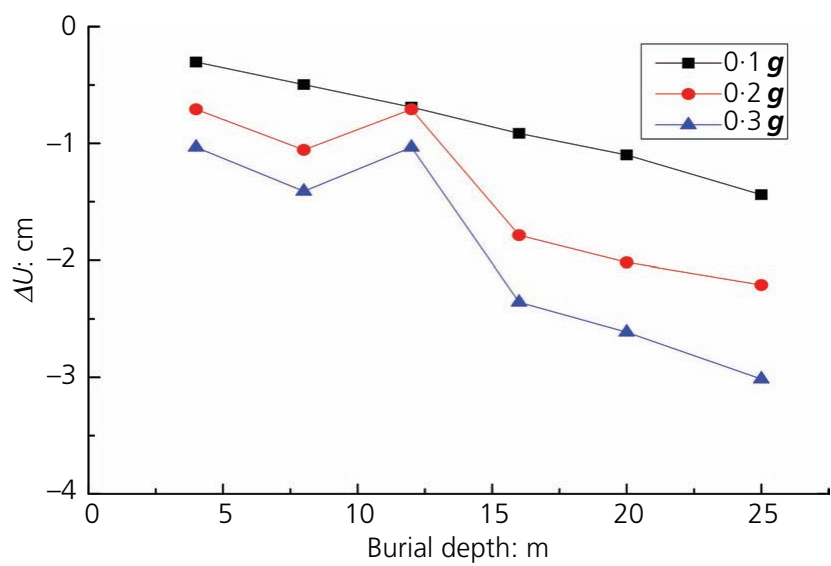

Figure 19. Variation in negative peak displacement difference at the side-plate of the subway station with burial depth

the other is the distance between the underground structure and the base rock where the wave comes. The effects of these two factors on the response of subway station are opposite to each other. The deeper the buried depth is, the stronger the constraint of the surrounding soil and the less the displacement difference, while the closer the distance between the underground structure and the base rock, the more the displacement difference. The occurrence of the declining segment is related to the strength of the effect of these two factors. That the soil exhibits only a linear behaviour under a small-earthquake condition can explain the linear result when the peak acceleration is $0 \cdot 1 \mathrm{~g}$.

\section{Conclusion}

This study comprehensively examines the problem of interaction among the elements of a multistructure system through soil. Considerable effort has been exerted to make the model as realistic as possible and to obtain accurate results. A rigorous 3D finiteelement model of the structure-soil-structure system is established in 
this work to discuss the influence of frame structures on underground structures under different parameters. The influences of four factors - namely, horizontal distance between the frame structures and subway station, length of the pile foundation, orientation of the frame structure and burial depth of the subway station - on the response of the underground structure is discussed in the time domain. An investigation in the time domain is a significant part of the analysis of the seismic behaviour of a multistructure system, which highly complements a frequency-domain analysis. The results are presented in terms of graphs and formulas.

Horizontal distance and burial depth are two key influencing factors given their distinct impacts on the interaction. The interstorey drift ratio response of the subway station is fluctuating, but not monotonous, under different conditions of horizontal distance, and the influence is slight when the distance is sufficiently far. The peak displacement difference increases with an increase in the burial depth of the underground structure, and both variables exhibit a linear growth trend when the acceleration peak of the earthquake motion is $0 \cdot 1 \mathrm{~g}$. While when the peak acceleration is $0.2 \boldsymbol{g}$ or $0.3 \boldsymbol{g}$, the peak displacement difference increases with the increase in burial depth overall and declines when the burial depth is $12 \mathrm{~m}$. The remaining parameters - namely, the length of the pile foundation and the orientation of the frame structure - contribute minimally to the response. The influences of these factors can be neglected relative to the first two factors.

Evidently, nearby buildings significantly affect the seismic response of underground structures according to the results of this study. Furthermore, an in-depth exploration on the SSSI problem should be conducted to analyse the seismic behaviour of structures under actual urban spatial arrangement conditions - for example, the seismic behaviour of a school near a subway station.

\section{Acknowledgements}

This study was financially supported by the National Key R\&D Program of China (Number 2016YFC0800200) and the National Natural Science Foundation of China (Numbers 51778260 and 51378234).

\section{REFERENCES}

Abate G and Massimino MR (2017a) Parametric analysis of the seismic response of coupled tunnel-soil-aboveground building systems by numerical modelling. Bulletin of Earthquake Engineering 15(1): 443-467, https://doi.org/10.1007/s10518-016-9975-7.

Abate G and Massimino MR (2017b) Numerical modelling of the seismic response of a tunnel-soil-aboveground building system in Catania (Italy). Bulletin of Earthquake Engineering 15(1): 469-491, https:// doi.org/10.1007/s10518-016-9973-9.

Abate G, Corsico S and Massimino MR (2016) FEM modelling of the seismic behavior of a tunnel-soil-aboveground building system: a case history in Catania (Italy). Procedia Engineering 158: 380-385, https:// doi.org/10.1016/j.proeng.2016.08.459.

Aldaikh H, Alexander NA, Ibraim E and Oddbjornsson O (2015) Two dimensional numerical and experimental models for the study of structure-soil-structure interaction involving three buildings.
Computers \& Structures 150: 79-91, https://doi.org/10.1016/j. compstruc.2015.01.003.

Aldaikh H, Alexander NA, Ibraim E and Knappett J (2016) Shake table testing of the dynamic interaction between two and three adjacent buildings (SSSI). Soil Dynamics and Earthquake Engineering 89: 219-232, https://doi.org/10.1016/j.soildyn.2016.08.012.

Azadi M and Hosseini SMMM (2010) Analyses of the effect of seismic behavior of shallow tunnels in liquefiable grounds. Tunnelling and Underground Space Technology 25(5): 543-552, https://doi.org/10. 1016/j.tust.2010.03.003.

Behnamfar F and Sugimura Y (1999) Dynamic response of adjacent structures under spatially variable seismic waves. Probabilistic Engineering Mechanics 14(1/2): 33-44, https://doi.org/10.1016/S02668920(98)00033-2.

Bobet A, Fernandez G, Huo H and Ramirez J (2008) A practical iterative procedure to estimate seismic-induced deformations of shallow rectangular structure. Canadian Geotechnical Journal 45(7): 923-938, https://doi.org/10.1139/T08-026.

Chen GX, Wang ZH, Zuo X, Du XL and Gao HM (2013) Shaking table test on the seismic failure characteristics of a subway station structure on liquefiable ground. Earthquake Engineering \& Structural Dynamics 42(10): 1489-1507, https://doi.org/10.1002/eqe.2283.

Chen GX, Chen S, Zuo X et al. (2015) Shaking-table tests and numerical simulations on a subway structure in soft soil. Soil Dynamics and Earthquake Engineering 76: 13-28, https://doi.org/10.1016/j.soildyn. 2014.12.012.

Guo J, Chen JY and Bobet A (2013) Influence of a subway station on the inter-story drift ratio of adjacent surface structures. Tunnelling and Underground Space Technology 35: 8-19, https://doi.org/10.1016/j. tust.2012.12.001.

Hashash YMA, Hook JJ, Schmidt B and Yao IC (2001) Seismic design and analysis of underground structures. Tunnelling Underground Space Technology 16(4): 247-293, https://doi.org/10.1016/S0886-7798(01) 00051-7.

Hatzigeorgiou GD and Beskos DE (2010) Soil-structure interaction effects on seismic inelastic analysis of 3-D tunnels. Soil Dynamics and Earthquake Engineering 30(9): 851-861, https://doi.org/10.1016/j. soildyn.2010.03.010.

Kausel E (2010) Early history of soil-structure interaction. Soil Dynamics and Earthquake Engineering 30(9): 822-832, https://doi.org/10.1016/j. soildyn.2009.11.001.

Kobori T and Kusakabe K (1978) Dynamic cross-interaction between two embedded structure. Proceedings of the Fifth Japan Earthquake Engineering Symposium, Tokyo, Japan, pp. 521-528.

Kobori T and Kusakabe K (1980) Cross-interaction between two embedded structures in earthquakes. Proceedings of the Seventh World Conference on Earthquake Engineering, Istanbul, Turkey, pp. 65-72.

Liu HB and Ling HI (2008) Constitutive description of interface behavior including cyclic loading and particle breakage within the framework of critical state soil mechanics. International Journal for Numerical and Analytical Methods in Geomechanics 32(12): 1495-1514, https://doi. org/10.1002/nag.682.

Liu HB, Song EX and Ling HI (2006) Constitutive modeling of soil-structure interface through the concept of critical state soil mechanics. Mechanics Research Communications 33(4): 515-531, https://doi.org/10.1016/j.mechrescom.2006.01.002.

Liu HB, Zou DG and Liu JM (2014) Constitutive modeling of dense gravelly soils subjected to cyclic loading. International Journal for Numerical and Analytical Methods in Geomechanics 38(14): 1503-1518, https://doi.org/10.1002/nag.2269.

Luco JE and Westman RA (1971) Dynamic response of circular footings. Journal of the Engineering Mechanics Division 97(5): 1381-1395.

Luco JE and Westmann RA (1972) Dynamic response of rigid footing bonded to an elastic half-space. Journal of Applied Mechanics 39(2): 527-534, https://doi.org/10.1115/1.3422711. 
Macari EJ, Hoyos LR and Arduino P (2003) Constitutive modeling of unsaturated soil behavior under axisymmetric stress states using a stress/suction-controlled cubical test cell. International Journal of Plasticity 19(10): 1481-1515, https://doi.org/10.1016/S0749-6419(02) 00018-9.

Martin PP and Seed HB (1982) One-dimensional dynamic ground response analyses. Journal of the Geotechnical Engineering Division 108(7): 935-952.

Miao Y, Yao EL, Luo H and Zhu HP (2016) Seismic behavior of soil-pile-structure interaction with a modified Desai thin-layer interface element. Advances in Mechanical Engineering 8(12): 1-11, https://doi.org/10.1177/1687814016680940.

Pyke RM, Pender MJ and Richart FE Jr (1979) Nonlinear soil models for irregular cyclic loadings. Journal of Geotechnical Engineering 105(6): 715-726.

Reissner E (1936) Stationäre, axialsymmetrische, durch eine schüttelnde Masse erregte Schwingung eines homogenen elastischen Halbraum. Ingenieur-Archiv 7(6): 381-396, https://doi.org/10.1007/BF02090427 (in German).

Romanel C and Kundu T (1993) A hybrid modelling of soil-structure interaction problems for deeply embedded structures in a multilayered medium. Earthquake Engineering and Structural Dynamics 22(7): 557-571, https://doi.org/10.1002/eqe.4290220702.
Wang HF, Lou ML, Chen X and Zhai YM (2013) Structure-soil-structure interaction between underground structure and ground structure. Soil Dynamics and Earthquake Engineering 54: 31-38, https://doi.org/10. 1016/j.soildyn.2013.07.015.

Wang HF, Lou ML, Chen X and Zhai YM (2017) Influence of presence of adjacent surface structure on seismic response of underground structure. Soil Dynamics and Earthquake Engineering 100: 131-143, https://doi.org/10.1016/j.soildyn.2017.05.031.

Warburton GB, Richardson JD and Webster JJ (1971) Forced vibrations of two masses on an elastic half space. Journal of Applied Mechanics - Transactions 38(1): 148-156, https://doi.org/10.1115/1. 3408735 .

Warburton GB, Richardson JD and Webster JJ (1972) Harmonic responses of masses on an elastic half space. Journal of Engineering for Industry 94(1): 193-200, https://doi.org/10.1115/1.3428111.

Yang SY, Jiang XL and Li XG (2007) Analysis on seismic response effect of tunnel to nearby structure. Journal of Sichuan University (Engineering Science Edition) 39(3): 41-46.

Zhao DF, Ruan B, Chen GX, Xu LY and Zhuang HY (2017) Validation of modified irregular loading-unloading rules based on Davidenkov skeleton curve and its equivalent shear strain algorithm implemented in Abaqus. Chinese Journal of Geotechnical Engineering 39(5): $888-895$.

\section{How can you contribute?}

To discuss this paper, please submit up to 500 words to the editor at journals@ice.org.uk. Your contribution will be forwarded to the author(s) for a reply and, if considered appropriate by the editorial board, it will be published as a discussion in a future issue of the journal. 